\title{
Agronegócio cooperativo: o caso de uma cooperativa de citros do Rio Grande do Sul
}

\author{
Cooperative agribusiness: the case of a citrus cooperative of Rio Grande do Sul
}

\begin{abstract}
Aline Zulian', Andrea Cristina Dorr², Katia Laura Sidali ${ }^{3}$
' Mestranda do Programa de Pós-Graduação em Economia e Desenvolvimento, Bacharel em Ciências Econômicas, Pesquisadora do Grupo de Pesquisa em Agronegócios, Universidade Federal de Santa Maria, Santa Maria, Brasil.

2 Professora Adjunta do Departamento de Educação Agrícola e Extensão Rural do Centro de Ciências Rurais,Professora Permanente do Programa de Pós-graduação em Extensão Rural, Coordenadora do Grupo de Pesquisa em Agronegócios, Universidade Federal de Santa Maria, Santa Maria, Brasil.

${ }^{3}$ Pesquisadora PhD na Unidade de Pesquisa Interdisciplinar sobre Propriedade Cultural, Universidade Georg-August, Göttingen, Alemanha.
\end{abstract}

\section{Resumo}

Este estudo justifica-se pela singularidade da cooperativa Ecocitrus localizada em Montenegro, na região do Vale do Caí, Rio Grande do Sul, que se especializou na citricultura orgânica e integrou verticalmente os elos da cadeia a fim de superar as dificuldades dos produtores individuais, que normalmente dependiam de intermediários. O objetivo geral desta pesquisa é verificar as vantagens do sistema cooperativista para os produtores sócios, através da identificação dos procedimentos adotados pela cooperativa. Os resultados indicam que os sócios são beneficiados pela existência da cooperativa através do acesso a novos mercados, da produção orgânica possibilitada pelo fornecimento gratuito composto orgânico pela cooperativa, do recebimento de assistência técnica e da diferenciação de produtos.

Palavras-chave: Cooperativa, citricultura, sistema agroindustrial..

\begin{abstract}
This study is justified by the uniqueness of the cooperative Ecocitrus located in Montenegro, in the Vale do Cai, Rio Grande do Sul, which specializes in organic citrus and vertically integrated chain links in order to overcome the difficulties of individual producers which usually depended on intermediaries. The overall goal of this research is to verify the advantages of the cooperative system for producers members, by identifying the procedures adopted by the cooperative. The results indicate that shareholders are benefited by the existence of the cooperative through access to new markets, organic production possible by providing free organic compound by the cooperative, the receipt of technical assistance and product differentiation.
\end{abstract}

Keywords: Cooperative, citriculture, agribusiness system. 


\section{INTRODUÇÃO}

A cadeia citrícola vem ganhando maior espaço no agronegócio brasileiro com a ampliação do mercado e o aprimoramento da atividade. Além de ser o maior produtor mundial de laranjas, o Brasil também é o maior exportador do suco de laranja, atendendo a diversos países. Segundo Neves et al. (2010, p. 08), em 2009, as exportações do complexo citros somaram de 2,9 milhões de toneladas, sendo que o Brasil é responsável por $50 \%$ da produção mundial de suco de laranja, e $98 \%$ do que ele produz é exportado. Ou seja, "de cada cinco copos de suco de laranja consumidos no mundo, três são produzidos nas fábricas brasileiras" e, além disso, "o suco de laranja é a bebida de frutas mais consumida no mundo, com 35\% de participação entre os sucos" (NEVES et al., 2010, p. 08).

Com o resultado desse sucesso na produção citrícola, de acordo com Neves et al. (2010), o PIB do setor foi de US\$ 6,5 bilhões em 2009, sendo US\$ 4,39 bilhões do mercado interno e US\$ 2,15 bilhões do mercado externo. Cabe destacar que outro setor que está ganhando destaque mundial dentro do sistema agroindustrial citrícola é o mercado de óleos essenciais cítricos. O Brasil encontra-se entre os principais países fornecedores dos óleos essenciais, ao lado da Índia, China e Indonésia, que são considerados os quatro grandes produtores mundiais (BIZZO; HOVELL; REZENDE, 2009, p. 588).

Contudo, para ter sucesso na produção agrícola, principalmente no caso de pequenos produtores, são necessárias medidas que envolvam mudanças na organização e preocupação com a diferenciação da produção no mercado. A cooperativa agropecuária pode apresentar-se como uma forma de possibilitar a eficiência econômica de pequenos produtores e a concorrência com grandes empresas do mercado. Ferreira (2009) afirma que o sistema cooperativo funciona como uma solução para os pequenos e médios produtores. De acordo com o mesmo autor, esse sistema é baseado na autogestão, e faz com que as cooperativas adotem estratégias de gestão adequadas e eficientes.

A região do Vale do Caí, no Rio Grande do Sul, possui destaque na produção de citros e influencia direta e indiretamente várias pessoas e setores da economia regional. Nesta região, existe a Cooperativa dos Citricultores Ecológicos do Vale do Caí, mais conhecida como cooperativa Ecocitrus, que reúne vários produtores que cultivam citros orgânico e, além de vender a fruta in natura, faz o processamento e a venda do suco cítrico e do óleo essencial de tangerina.

Apesar da competitividade reconhecida no ambiente nacional e internacional, a cadeia citrícola brasileira apresenta alguns entraves, principalmente relacionados a comercialização. São barreiras tarifárias e sanitárias que acabam encarecendo e muitas vezes inviabilizando o comércio externo da fruta ou do suco.

Devido à ampla competitividade e exigências do setor, o pequeno produtor encontra dificuldade de inserir-se no mercado e de manter-se nele. O presente trabalho justifica-se pela singularidade da cooperativa Ecocitrus que, ao contrário de outras unidades econômicas que também tem foco na agricultura, especializou-se apenas no segmento da citricultura orgânica e integrou verticalmente os elos da cadeia, a jusante e a montante, objetivando superar as dificuldades dos produtores individuais que normalmente dependiam de intermediários. Além disso, é importante investigar os procedimentos utilizados pela cooperativa para potencializar o crescimento da atividade citrícola na região, evidenciado tanto pelo cultivo das frutas orgânicas quanto pelo processamento do suco e do óleo essencial orgânico.

Tendo em vista a importância da citricultura para a região do Vale do Caí e a participação da cooperativa Ecocitrus no processo de inclusão de pequenos produtores da região, o objetivo principal deste estudo consiste em verificar as vantagens do sistema cooperativista para os produtores sócios, através da identificação dos procedimentos adotados pela cooperativa. Para a descrição da citricultura e do agronegócio cooperativo, desenvolveu-se uma pesquisa bibliográfica. E, para a obtenção de informações específicas da cooperativa e de seus associados, desenvolveram-se formulários semi-estruturados aplicados sob forma de entrevista para 24 sócios agricultores e para um sócio trabalhador (responsável pela administração da cooperativa).

\section{I.I AgRIBUSINESS E SISTEMA DE COMMODITIES (CSA)}

Após pesquisas realizadas, John Davis e Ray Goldberg, da Universidade de Harvard, em 1957, constataram que a agricultura não poderia ser analisada de forma isolada dos outros processos que envolviam a produção, transformação, comercialização e consumo de produtos agrícolas. Desse modo, foi criado o termo "agribusiness", ou "agronegócio": "a soma das operações de produção e distribuição de suprimentos agrícolas, das operações de produção das unidades agrícolas, do armazenamento, 
processamento e distribuição dos produtos agrícolas e itens produzidos a partir deles (DAVIS; GOLDBERG, 1957, p. 2)".

O agronegócio representa um conjunto de atividades além das fronteiras da propriedade rural (agrícola ou pecuária). Envolve, além dos produtores rurais, agentes que não estão ligados diretamente ao campo, como as indústrias fornecedoras de insumos, transformadoras e transportadoras, e todos os elos envolvidos com a comercialização do produto até chegar ao consumidor final (MENDES; PADILHA JUNIOR, 2007).

Segundo Neves (1995, p. 6), a concepção da agricultura brasileira até meados do século XX englobava todas as atividades desde a produção de insumos agropecuários até a comercialização do produto final. Ou seja, de acordo com a mesma fonte: "tudo era agricultura". Mas, com a modernização agrícola - produção de fertilizantes, defensivos, máquinas e implementos, ração e medicamento animal, operações de financiamento e de pesquisa -, o termo que conceituava a agricultura foi se aprimorando, já que muitas dessas funções foram designadas a terceiros e não mais ao produtor rural. Neves $(1995$, p. 6) afirma que "hoje o termo agricultura significa a atividade de plantio, condução e colheita, ou mesmo, a produção de animais, apenas o dentro da porteira". Juntamente com esta ideia está a concepção de agribusiness. De acordo com Neves (1995), o agribusiness recupera esse antigo conceito de agricultura, compreendendo tanto as atividades agrícolas, de antes e depois da porteira, quanto as negociações.

Após o desenvolvimento do conceito de agribusiness, Goldberg (1968 apud BATALHA; SILVA, 2009 , p. 5) definiu a noção de Commodity System Approach (CSA), ou Sistema de Commodities, que foi utilizada para um estudo na Flórida sobre o comportamento de três sistemas, respectivamente: trigo, soja e laranja, tendo as matérias-primas como ponto de partida para a análise.

A diferença básica entre agronegócio e a definição de CSA é que, conforme Goldberg (1968 apud CLARO et al., 1999, p. 20), a segunda tem uma definição mais restrita, utilizada para a análise de setores isolados ou produtos isolados. "É uma análise por produto, envolvendo seu fluxo desde a pesquisa até o consumidor final" (CLARO et al., 1999, p. 20). Assim, Zylbersztajn (2005, p. 7) aponta algumas características do estudo de Goldberg sobre o CSA: a) foca no sistema de apenas um produto, o que caracterizou a ideia de sistemas de agribusiness; b) define um "locus geográfico", como foi o caso da laranja na Flórida (delimitação do campo de estudo); c) utiliza o conceito de coordenação entre os elos da cadeia; d) e, enfatiza as diferenças dos sistemas do agribusiness dos outros sistemas industriais.

\section{I.2 CoOperativas}

As primeiras ideias cooperativas surgem durante o século XVIII na Inglaterra com a finalidade de fornecer bens de consumo com preços mais acessíveis às classes mais baixas (SOUZA, 1990). Com isso, começam a surgir personagens que difundiam esses ideais, sendo um deles Robert Owen (17711858). Estes, conforme Souza (1990), auxiliaram na organização de cooperativas e deixaram grande número de seguidores, como alguns dos fundadores da cooperativa de Rochdale. "Owen foi o criador do termo cooperação, em seu sentido econômico" (SOUZA, 1990).

Foi em Rochdale, pequena cidade perto de Manchester na Inglaterra, em 1844, que surgiu o "moderno" movimento cooperativista: uma cooperativa de consumo originada de uma greve fracassada de trabalhadores do setor têxtil (SOUZA, 1990).

Vários autores partiram dos princípios de Rochdale para propagar os ideais cooperativistas. Os Princípios Originais do Cooperativismo, de Rochdale e codificados por Charles Gide, são: "1) livre adesão; 2) gestão democrática; 3) juros limitados ao capital; 4) retorno proporcional às compras; 5) neutralidade política e religiosa; 6) transações a dinheiro; 7) constituição de fundo de reserva para educação dos cooperados" (SOUZA, 1990).

Essa base doutrinária do estatuto de Rochdale prevalece até os dias de hoje, sendo propagada pela Aliança Cooperativa Internacional (ACI), órgão máximo do movimento cooperativista mundial, criado em 1895. Os princípios doutrinários do cooperativismo, conforme Bialoskorski Neto (2009, p. 713), resumem-se filosoficamente em "liberdade, igualdade, fraternidade e solidariedade", expressas nas ideias cooperativas do estatuto de Rochdale.

No Brasil, a Lei ${ }^{\circ}$ 5.764, de 16 de dezembro de 1971, regulamenta a existência de sociedades cooperativas e contempla princípios da ACI. No artigo $4^{\circ}$ desta Lei (BRASIL, 1971) consta que "as cooperativas são sociedades de pessoas, com forma e natureza jurídica próprias, de natureza civil, não sujeitas a falência, constituídas para prestar serviços aos associados". Nos artigos 32 e 42 desta mesma 
Lei, citado por Bialoskorski Neto (2009, 713-4), a sociedade cooperativa é caracterizada como uma atividade econômica de proveito comum sem o objetivo de lucro, de adesão voluntária, com variabilidade do capital social representado por quotas-partes, inacessibilidade das quotas-partes, direito a um único voto, retorno das sobras líquidas do exercício, neutralidade política e religiosa, etc.

Além desta Lei específica, a Constituição Federal Brasileira de 1988 também trata do cooperativismo. Alguns artigos que fazem menção são: art. $5^{\circ}$, inciso XVIII, em que a criação de associações e de cooperativas não dependem de autorização, sendo vedada a interferência estatal em seu funcionamento; art. 146, inciso III, item c, demonstrando que a lei deve contemplar um adequado tratamento tributário ao ato cooperativo praticado pelas sociedades cooperativas; o art. 174, parágrafo $2^{\circ}$, obriga o Estado a apoiar e estimular o cooperativismo e outras formas de associativismo (BRASIL, 1988).

Entre outros atributos existentes, as cooperativas distinguem-se das demais sociedades pelo fato dos indivíduos associarem-se na organização não pelo objetivo de obtenção de lucros proporcionais ao capital investido, mas para utilizar-se dos serviços ofertados pela cooperativa (FRANKE, 1973, p.13). Outra característica que diferencia uma cooperativa é que nesta cada sócio tem direito a apenas um voto nas assembléias, e na sociedade empresária o voto é proporcional a participação do sócio no capital da empresa.

\section{I.3 Agronegócio cooperativo}

Para Bialoskorski Neto (2009), há uma recente tendência no cooperativismo conhecida como Nova Geração de Cooperativas (NGC's). Ele aponta a importâncias das cooperativas para o agronegócio brasileiro em função principalmente da agregação de valor às commodities agrícolas e ao poder de barganha por parte do produtor. Mas o autor defende que as vantagens só existirão se forem modificados os direitos de propriedade presente na antiga doutrina cooperativista, permitindo maior eficiência econômica para a cooperativa. Bialoskorski Neto (2009, p. 726) descreve o que seria essa Nova Geração de Cooperativas (NGC): "definida como uma forma de arquitetura do empreendedorismo cooperativo que mantém os princípios doutrinários do cooperativismo [...], mas que traz modificações nos direitos de propriedade, para induzir a organização cooperativa a um nível maior de eficiência econômica".

Nesse caso, a visão e o objetivo inicial são os de mercado e não mais dos produtores, e cada associado deve contribuir com o capital do novo empreendimento proporcional a produção que ele entregará futuramente para a cooperativa (BIALOSKORSKI NETO, 2009, p. 726). Esse valor, segundo o mesmo autor, será a quota de participação de cada associado, permitindo que ele transacione com sua cooperativa o valor já estipulado anteriormente e com a qualidade também pré-estipulada. Bialoskorski Neto $(2009$, p. 127) acrescenta que os direitos de uso da planta processadora da cooperativa são transferíveis, o que garante que o investimento realizado pelo produtor seja uma reserva de valor. Ou seja, "essas organizações mantêm os princípios doutrinários e os objetivos da cooperação, mas, por outro lado, permitem que haja estímulo e incentivo no incremento da eficiência econômica e coordenação do sistema agroindustrial" (BIALOSKORSKI NETO, 2009, p. 727).

Segundo levantamento da Aliança Cooperativa Internacional (ACI, 2011), existem aproximadamente 1 bilhão de membros de cooperativas em 90 países, o equivalente a $1 / 7$ da população da Terra. Ou seja, "a cada sete pessoas no mundo, uma está associada a uma cooperativa", sendo que só no Brasil, "estima-se em 30 milhões o número de pessoas envolvidas com o cooperativismo" (SESCOOP, 2011).

Em 2010, segundo a Organização das Cooperativas Brasileiras (OCB, 2010), havia 6.652 cooperativas no Brasil. Deste montante, a maior parte, $23 \%$, pertence ao ramo agropecuário, que teve 943.054 associados e 146.011 empregados em 2010. De acordo com a OCB (2010), 49\% do total de empregos diretos gerados pelos diferentes ramos de cooperativas (crédito, trabalho, saúde, educação, transporte, etc.) foram proporcionados pelas cooperativas agropecuárias. Isso evidencia a importância da cooperativa não apenas para o produtor associado, mas também para o mercado de trabalho.

Outro importante levantamento feito pela OCB foi que houve um aumento considerável nos produtos exportados oriundos das cooperativas agropecuárias: de 2000 a 2010 as exportações desses produtos aumentaram 582\%, obtendo um total de US $\$ 4,4$ bilhões em exportações diretas (OCB, 2010).

A importância do cooperativismo é percebida também na recente decisão da Organização das Nações Unidas (ONU) "que definiu o ano de 2012 como o Ano Internacional das Cooperativas, colocando o cooperativismo em evidência no mundo" (SESCOOP, 2012). A frase dita pelo Secretário Geral da ONU, Ban Ki-moon, justifica essa decisão: "As cooperativas demonstram para a comunidade internacional que é possível perseguir tanto a viabilidade econômica quanto a responsabilidade social" 


\section{(SESCOOP, 2012).}

Gimenes e Gimenes (2006) abordaram a importância do cooperativismo agropecuário na cadeia de valor do agronegócio nacional. Eles concluem que o principal desafio das sociedades cooperativas é a de manter-se como uma empresa competitiva, capaz de enfrentar multinacionais de grande porte e, ao mesmo tempo, atender às necessidades dos seus associados. E isso impõe limites à expansão das cooperativas com recursos próprios (autofinanciamento), que são limitados, necessitando, assim, de recursos financeiros de terceiros.

Além de incentivar a criação de cooperativas agropecuárias, é importante a prática da gestão, uma vez que a entidade envolve um grande grupo de pessoas e se relaciona com o mercado competitivo. Ferreira (2009) afirma que o sistema cooperativo funciona como uma solução para os pequenos e médios produtores. Esse sistema é baseado na autogestão, e faz com que as cooperativas adotem estratégias de gestão adequadas e eficientes. $\mathrm{O}$ autor cita ferramentas administrativas e contábeis de gestão e evidencia a importância destas no processo decisório na cadeia do agronegócio cooperativo.

Jerônimo, Maraschin e Silva (2006) também abordam o tema da gestão nas sociedades cooperativas, com foco numa cooperativa agropecuária gaúcha. O estudo de caso objetivou identificar e analisar a gestão estratégica de uma cooperativa agropecuária do setor alimentar, localizada no Vale do Taquari, região noroeste do estado do Rio Grande do Sul. Algumas das conclusões do estudo foram de que os principais entraves de gestão estratégica em cooperativas estão associados à limitação de recursos, à cultura e à deficiência na tomada de decisão. Por outro lado, segundo o mesmo trabalho, as cooperativas agropecuárias, em especial, demonstram contar com pontos fortes, por terem acesso à produção agropecuária, e contarem com a possibilidade de coordenar a produção.

Uma estratégia de organização no agronegócio é a integração vertical. Esta constitui-se de um conjunto de atividades que compõem o agronegócio de um ou mais produtos, incluindo os setores "antes, durante e após a porteira", tendo como gestora uma empresa (cooperativa, sociedade anônima, condomínios) que coordena as atividades (ARAÚJO, 2003 apud SILVA, 2006, p. 14). Esta foi a opção adotada pela cooperativa Ecocitrus, que é responsável pelos processos de fabricação de insumos e pela agroindustrialização e geração do produto final. Ou seja, para a adoção da estratégia de integração vertical, a firma deve participar de vários estágios: desde o preparo da matéria-prima até a comercialização do produto final (SILVA, 2006, p. 35). Conforme Silva (2006, p. 16), "a integração vertical leva à garantia de fornecimento, à redução de custos por parte das empresas integradas, e, por fim, à redução dos preços finais para o consumidor".

\section{METODOLOGIA}

\section{I ÁREA DE ESTUDO}

A citricultura não é a principal atividade agrícola dos produtores do Rio Grande do Sul, por isso não se encontram muitas informações a respeito desta atividade no estado. Apesar disso e de a produção estar sujeita as variações climáticas, ela apresenta uma tendência de crescimento na quantidade produzida desde 2009 (IBGE, 2011).

A quantidade de laranja produzida pelo Rio Grande do Sul em 2011, segundo a base de dados da Produção Agrícola Municipal (IBGE, 2011), foi de 391.692 toneladas, representando cerca de $31 \%$ da produção de laranjas da região sul do Brasil e $2 \%$ da produção total brasileira de laranjas. Já a produção gaúcha de tangerinas, que em 2011 foi de 156.285 toneladas, representa $47 \%$ da produção da região sul e $15 \%$ do total de tangerinas produzidas no Brasil. Conforme o Hasse (2010), a variedade de tangerina mais cultivada no Rio Grande do Sul, abrangendo mais de 50\% dos pomares, é a Montenegrina, que representa cerca de $15 \%$ da produção cítrica gaúcha, que é dominada pelas laranjas.

Nos 20 municípios que compreendem a região do Vale do Caí, próxima a região metropolitana de Porto Alegre-RS, destacam-se Montenegro, Harmonia, Pareci Novo, São Sebastião do Caí, Bom Princípio e Salvador do Sul, onde a citricultura desenvolve um papel fundamental para o desenvolvimento regional. Em torno de 4.000 famílias desta região, conforme a divulgação da Prefeitura Municipal de Montenegro (2011), consideram a citricultura como a principal fonte de renda.

No Vale do Caí, principalmente nas municipalidades de Montenegro, Harmonia e Pareci Novo, a produção média de citros é de 10 toneladas por hectare, com uma área produtiva com cerca de 7.500 hectares (SLOW FOOD BRASIL, 2007). Segundo a mesma fonte acima, a produção total de tangerina, 
principal fruta cultivada, é de cerca de 110 mil toneladas por ano.

A citricultura proporciona empregos em diferentes segmentos: plantio, colheita, transporte, armazenamento, tanto nas cooperativas quanto nas indústrias de beneficiamento da fruta. Além disso, o comportamento do setor de comércio e de serviços das cidades que compreendem o Vale do Caí está diretamente relacionado com o período das safras obtidas na produção de citros (PREFEITURA MUNICIPAL DE MONTENEGRO, 2011).

As principais potencialidades e facilidades da região são: solo e clima favoráveis para o cultivo dos citros, proximidade dos centros de comercialização, bom número de comerciantes na região, o grande volume de fertilizante orgânico de aves e suínos disponível na região, as experiências na produção ecológica de citros e o manejo do solo com cobertura vegetal permanente em alguns pomares (PREFEITURA MUNICIPAL DE MONTENEGRO, 2011).

Mais especificamente, analisou-se a cooperativa Ecocitrus, Cooperativa dos Citricultores Ecológicos do Vale do Caí, localizada no município de Montenegro, Rio Grande do Sul, Brasil. Esta faz o processamento do óleo essencial de tangerina, além de fabricar o suco e também vender a fruta in natura.

\subsection{CARACTERIZAÇÃo DA PESQUisa}

Essa pesquisa é caracterizada como exploratória, uma vez que objetiva proporcionar maior familiaridade com o problema levantado e envolve desde pesquisa bibliográfica até pesquisa de campo com entrevistas para os agentes envolvidos no estudo (GIL, 2009).

De modo geral, esta pesquisa enquadra-se no método de procedimento de estudo de caso uma vez que busca levantar o máximo de informações possíveis e investigar a situação da cadeia citrícola para uma determinada cooperativa de citros do Rio Grande do Sul. O estudo de caso é aplicável quando se deseja obter generalizações analíticas e não estatísticas que possam contribuir para certo referencial teórico (LAZZARINI, 1997), de modo que as conclusões de um estudo como este não podem ser generalizadas (GIL, 2009). A pesquisa por meio de estudos de caso tem sido enquadrada no grupo de métodos denominados qualitativos, que se caracteriza por um maior foco na compreensão dos fatos do que propriamente na sua mensuração (LAZZARINI, 1997). Dessa forma, contrasta-se com os métodos quantitativos, que se preocupam mais em mensurar fenômenos e são aplicados a amostras mais extensas (LAZZARINI, 1997).

\subsection{Coleta e ANÁlise de dAdos}

A Ecocitrus é composta por cerca de 110 associados (Figura 01), sendo que 7 são agricultores e trabalhadores, 42 são apenas trabalhadores da cooperativa (trabalham na usina de compostagem, agroindústria ou sede administrativa) e 61 são agricultores (cultivam citros e destinam a produção para a cooperativa). No geral, estão envolvidas diretamente com a instituição, aproximadamente, 150 famílias (ECOCITRUS, 2010).

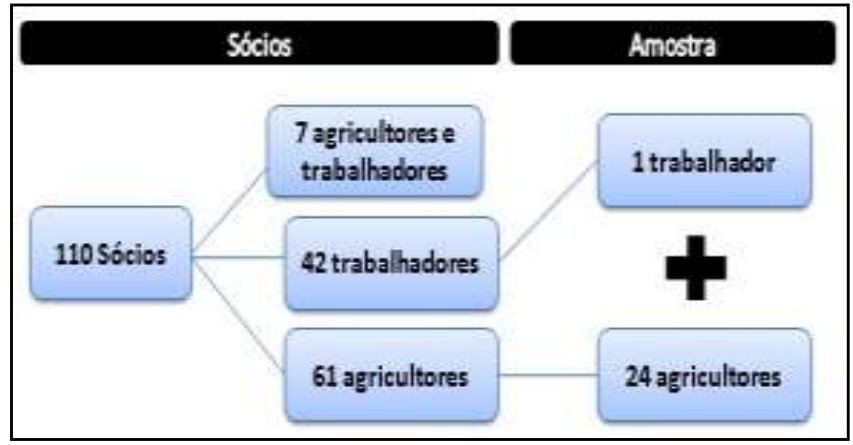

Figura 01 - População e Amostragem

Dessa forma, conforme a Figura 01, entrevistou-se um responsável pela administração da cooperativa (sócio trabalhador) e 24 sócios agricultores, escolhidos aleatoriamente, com o intuito de conhecer a participação dos sócios e as vantagens obtidas do cooperativismo e de caracterizar o sistema agroindustrial citrícola da Ecocitrus. A coleta dos dados primários consistiu-se na aplicação de 
um formulário semi-estruturado com perguntas abertas tanto para os produtores sócios quanto para um responsável pela cooperativa.

Após coletados os dados, estes foram analisados principalmente qualitativamente. Uma vez que a pesquisa enquadra-se num estudo de caso e não objetiva generalizações, buscou-se relevar as informações principalmente da ordem qualitativa, afim de conhecer os procedimentos adotados pela cooperativa Ecocitrus e a visão dos sócios sobre a entidade. No que se refere a respostas de cunho qualitativo, apenas utilizou-se a média entre as respostas para melhor simplificação. Para tabulação dos dados e organização destes, utilizou-se o Microsoft Office Excel 2007.

\section{RESULTADOS E DISCUSSÕES}

\section{I Cooperativa Ecocitrus}

A Ecocitrus foi formada em 1994, em Montenegro-RS, na região do Vale do Caí, como uma ideia alternativa à agricultura convencional: cultivar frutas cítricas sem a utilização de agroquímicos. Com a preocupação de manter a família no campo, diminuir os custos de produção, principalmente com agrotóxicos, e reduzir a poluição dos arroios e rios, os produtores optaram por cultivar frutas usando apenas adubo orgânico.

Os produtores membros da cooperativa Ecocitrus possuem certificação Orgânica, de Comércio Justo (FLO) e o selo Ecovida. A certificação Orgânica ocorre através do selo IBD Orgânico, sendo o IBD (Instituto Biodinâmico) a maior certificadora da América Latina e a única certificadora brasileira de produtos orgânicos aceito globalmente (IBD, 2012). Em média, o total anual gasto pela cooperativa para manutenção deste selo é de $\mathrm{R} \$ 10.000,00$, incluindo a auditoria e a renovação.

O selo FLO (Fairtrade Labelling Organizations), conhecido como Fairtrade ou Comércio Justo, representa a garantia de que o produtor rural está recebendo um preço justo (que cobre os seus custos de produção), respeitando o meio ambiente (FAIRTRADE, 2007). As normas dessa certificação são muito rígidas e o custo desse selo para a cooperativa é de em torno $\mathrm{R} \$ 3.434,00$ por ano.

Por fim, o selo Ecovida representa a Rede de Agroecologia Ecovida, que conta com 23 núcleos regionais e aproximadamente 170 municípios no Paraná, Rio Grande do Sul e Santa Catarina (ECOVIDA, 2012).

\subsection{Cadeia AGRoindustrial}

A cadeia agroindustrial da cooperativa Ecocitrus é descrita pela Figura 02. Ela mostra desde a produção dos insumos para o cultivo das frutas orgânicas, o processamento, o acondicionamento, a comercialização, até chegar ao consumidor final. Entre essas etapas existem os serviços de apoio: certificadoras, bancos, profissionais, institutos de pesquisa, universidades, marketing, etc. E interessante destacar que a cooperativa buscou a verticalização dos processos a fim de eliminar os intermediários e aumentar os ganhos para o produtor. Conforme Williamson (1979 apud ALBUQUERQUE; FLEURY; FLEURY, 2010), "a definição microeconômica de integração vertical implica o envolvimento de uma empresa em mais de um estágio da cadeia de um determinado processo produtivo".

Essa cadeia beneficia todos os segmentos envolvidos por ela. Isso é percebido também pela opinião dos produtores sócios entrevistados, que se demonstraram muito satisfeitos com a cooperativa. Estes afirmaram que as principais vantagens em ser um sócio são: acesso a novos mercados, garantia de venda da produção, possibilidade de difusão do conhecimento entre os associados (são realizados cursos e palestras), o adubo orgânico e o fertilizante líquido são fornecidos e aplicados gratuitamente pela cooperativa, a parte burocrática e as negociações para comercialização ficam a cargo da cooperativa.

Dessa maneira, a cooperativa ganhou diferenciação no mercado. As etapas do processo agroindustrial da Ecocitrus serão descritas abaixo.

\subsection{Usina de compostagem}

Os insumos orgânicos (composto sólido e fertilizante líquido) utilizados nas propriedades dos sócios são processados pela própria cooperativa, que possui a Usina de Compostagem de Resíduos Agroindustriais para este fim. A usina foi criada em 1995 para a recuperação das áreas plantadas, com um investimento de $\mathrm{R} \$ 78.000,00$.

O foco da usina é a reutilização de resíduos já resultantes de um processo produtivo. Ela recebe resíduos orgânicos de 35 empresas da região, faz o processamento transformando-os em adubo orgânico 
e realiza a distribuição gratuita para os sócios. A cooperativa recicla anualmente um total de 45 mil toneladas de resíduos industriais e produz 15.000 toneladas de composto orgânico (sólido) e 15.000 toneladas de biofertilizante líquido por ano.

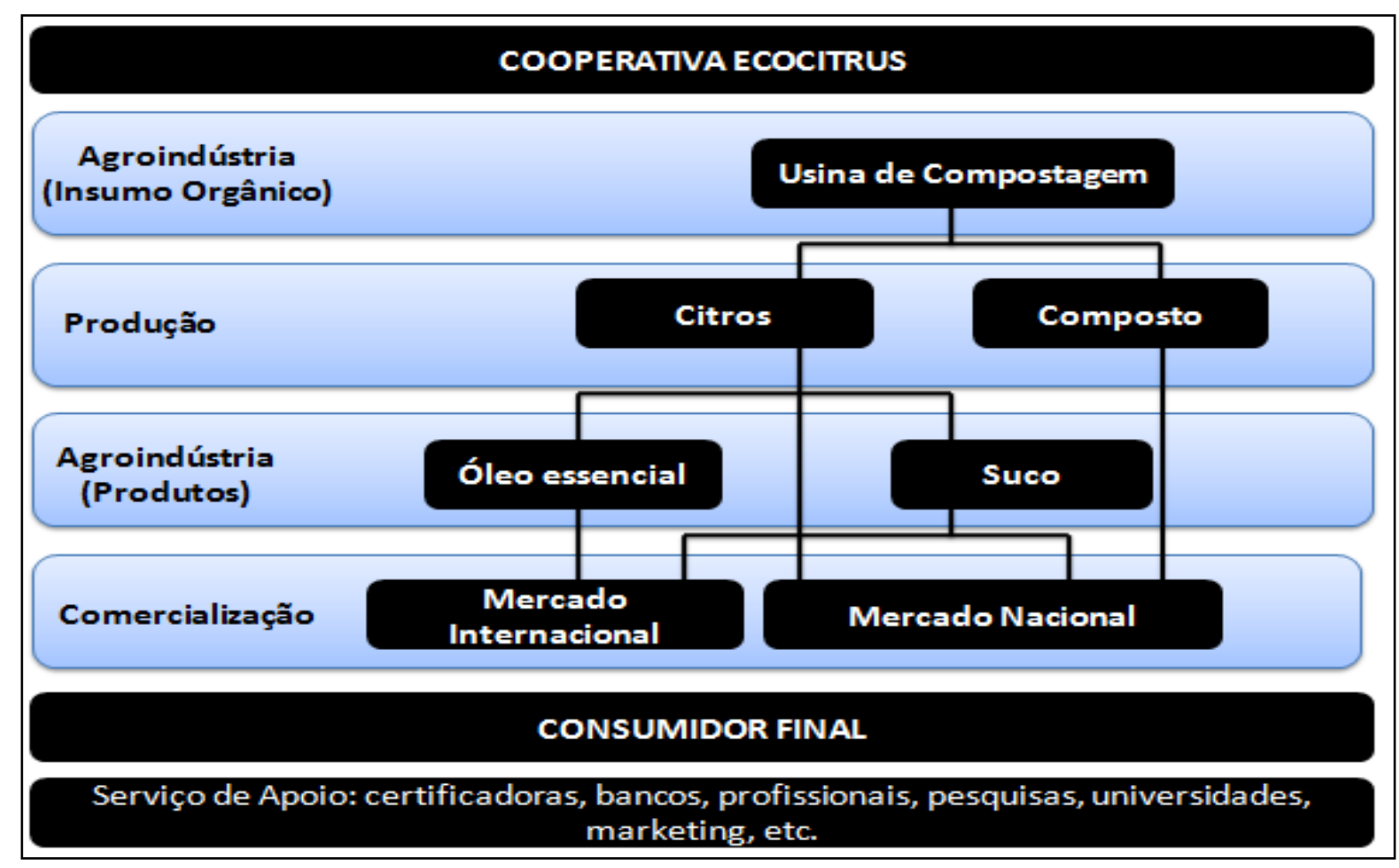

Figura 02 - Cadeia agroindustrial da Ecocitrus

Os produtos são destinados para os sócios da cooperativa e também para terceiros. Os sócios não têm custo com o composto, o transporte e a aplicação deste em suas propriedades. Eles recebem somente a quantidade que a equipe técnica da cooperativa julga ser suficiente para a área a ser aplicada. Além disso, esta equipe faz constantes análises de solo e das folhas nas propriedades dos sócios.

Os preços desses insumos orgânicos produzidos são diferenciados, com exceção dos sócios, que não tem custo algum. Assim, o preço do composto orgânico para os indivíduos que não são sócios da cooperativa é de $\mathrm{R} \$ 40,00$ por metro cúbico, e para os produtores sócios, mas que estão ainda possuem as terras da propriedade em transição para a produção orgânica (esse processo demora no mínimo um ano) é 50\% mais barato. Esta é uma ação para difundir a prática orgânica e ecológica. Além de vender o composto orgânico, a usina presta serviços de transformação de resíduos em composto orgânico para as empresas industriais. O preço médio da prestação de serviços é de $\mathrm{R} \$ 60,00$.

A usina de compostagem tem um faturamento mensal de $\mathrm{R} \$ 300.000,00$, sendo que obtém uma rentabilidade de $50 \%$ deste faturamento, valor que é investido na própria cooperativa. O custo com pessoal representa $20 \%$ deste faturamento. O custo com energia é de $\mathrm{R} \$ 5.000,00 /$ mês, além do aluguel da área e de custos com equipamentos e combustíveis.

\subsubsection{Processo produtivo}

A principal fruta produzida e comercializada, tanto in natura quanto em suco ou óleo essencial, é a tangerina. As espécies cultivadas pelos sócios são: Montenegrina, Caí, Pareci, Satsuma, Ponkan e Murcott. Apesar de ser produzida num montante menor, a laranja é cultivada nas espécies: Umbigo, Céu, Valência e Seleta. Além destas, existe a produção de lima e limão em menor quantidade.

Os produtores possuem entre 12 a 15 hectares de área total, onde $60 \%$ ou mais é composto pelo pomar de citros. A renda obtida com a venda de citros representa a renda mais importante da família.

Conforme dados fornecidos pela cooperativa Ecocitrus, apresentados na Figura 03, a produção de frutas vem aumentando desde 2008, chegando em $2010 \mathrm{com}$ um total de $2.873 .512 \mathrm{~kg}$ de frutas produzidas. Esse valor caiu um pouco em 2009 em função, principalmente, da forte geada ocorrida 
naquele ano que prejudicou a geração do fruto.

A produção de tangerinas, que abrange $58 \%$ do que é produzido na cooperativa, juntamente com as tangerinas verdes (colhidas antes da sua maturação para exclusivamente a produção do óleo essencial) que totaliza $33,8 \%$ da produção total, são responsáveis por $91,8 \%$ da produção geral da cooperativa. Isso deixa claro que a principal fruta cultivada pela cooperativa é a tangerina, destinada ao mercado sobre diferentes formas: in natura, suco e óleo essencial.

Com relação aos preços pagos aos produtores por quilograma de cada fruta, pode-se analisar a Figura 04. Os preços recebidos pelos produtores mantém certa estabilidade, variando poucos centavos de um ano para outro.

A tangerina madura atingiu em 2010 um preço de $\mathrm{R} \$ 0,34$ por quilograma e $\mathrm{R} \$ 0,18$ o quilograma de tangerina verde. Apesar de ter ocorrido uma pequena redução no preço recebido por quilograma de tangerina madura entre 2009 e 2010, houve aumento nos preços das demais frutas entre esses anos. Dessa forma, o total produzido pela cooperativa em 2010 de 2.873 .512 quilogramas de frutas gerou um total de $\mathrm{R} \$ 826.309,37$ destinados aos produtores, uma média geral de $\mathrm{R} \$ 0,29$ por quilograma de citros produzido. Esse aumento no montante final destinado ao pagamento dos produtores pelas frutas é acompanhado do aumento da produção total, o que não faz alterar o preço por quilograma geral, que se manteve em R $\$ 0,29$ em 2009 e 2010.

Cabe destacar que a espécie de tangerina que tem o maior valor pago ao produtor é a Montenegrina. A média de preço pago ao produtor da cooperativa por quilograma da tangerina Montenegrina madura, durante esses três anos, foi de $\mathrm{R} \$ 0,37$, estando acima do preço médio geral de tangerinas, que variou de $\mathrm{R} \$ 0,30 \mathrm{em} 2008$ para $\mathrm{R} \$ 0,34 \mathrm{em}$ 2010. A tangerina Montenegrina possui preços diferenciados, podendo alcançar o dobro ou o triplo em relação a variedades mais abundantes e precoces (colhidas a partir de Março e Abril) (HASSE, 2010).

\begin{tabular}{|c|c|c|c|c|c|c|}
\hline \multirow{2}{*}{ Fruta } & \multicolumn{2}{|c|}{ Produção 2008} & \multicolumn{2}{|c|}{ Produção 2009} & \multicolumn{2}{|c|}{ Produção 2010} \\
\hline & kg & $\%$ & kg & $\%$ & kg & $\%$ \\
\hline Tangerina & 1.265 .957 & 45,1 & 728.398 & 47,7 & 1.666 .534 & 58,0 \\
\hline Tangerina Verde & 1.104 .087 & 39,3 & 335.995 & 22,0 & 972.249 & 33,8 \\
\hline Laranja & 406.906 & 14,5 & 437.080 & 28,6 & 214.710 & 7,5 \\
\hline Limão & 11.289 & 0,4 & 15.312 & 1,0 & 9.122 & 0,3 \\
\hline Lima & 19.460 & 0,7 & 10.980 & 0,7 & 10.897 & 0,4 \\
\hline Total & 2.807 .699 & 100 & 1.527 .765 & 100 & 2.873 .512 & 100 \\
\hline
\end{tabular}

Figura 03 - Produção da Cooperativa Ecocitrus de 2008 a 2010

Fonte: Elaborado pela autora com dados fornecidos pela Cooperativa Ecocitus

Segundo o site da Slow Food Brasil (2007) a bergamota Montenegrina resultou da mutação espontânea, descoberta em 1940 em Campo do Meio, no município de Montenegro-RS, por um agricultor de origem alemã. Algumas características dessa variedade são: fruta saborosa, casca resistente, e produz frutos tardios, entre Setembro e Outubro. Conforme a reportagem do Hasse (2010) feita na mesma região, nos pomares do Vale do Caí, onde a variedade Montenegrina predomina, é comum encontrar na primavera bergamoteiras de Montenegrinas carregadas de flores, uma vez que, apesar de em alguns pomares a fruta ser colhida a partir de Julho, a safra vai até Setembro-Outubro.

\subsubsection{Agroindústria}

Além de a cooperativa possuir a sua sede administrativa e a usina de compostagem em Montenegro-RS, ela também possui uma agroindústria de processamento e envasamento do suco de laranja e tangerina e do óleo essencial de tangerina. Essa agroindústria possui toda estrutura necessária para a finalização do processo produtivo, incluindo a presença de duas câmaras frias para armazenamento das frutas e de equipamentos necessários para os processos que envolvem a fabricação do suco, o 


\begin{tabular}{|c|c|c|c|c|c|c|c|c|c|}
\hline \multirow[b]{2}{*}{ Fruta } & \multicolumn{3}{|c|}{ Produção 2008} & \multicolumn{3}{|c|}{ Produção 2009} & \multicolumn{3}{|c|}{ Produção 2010} \\
\hline & kg & RS & $\begin{array}{l}\text { RS/ } \\
\text { kg }\end{array}$ & kg & RS & \begin{tabular}{|c|}
$\mathbf{R S} /$ \\
$\mathbf{k g}$ \\
\end{tabular} & kg & RS & \begin{tabular}{|l} 
RS/ \\
kg
\end{tabular} \\
\hline Tangerina & 1.265 .957 & $379.331,77$ & 0,30 & 728.398 & $260.831,83$ & 0,36 & 1.666 .534 & $564.526,92$ & 0,34 \\
\hline $\begin{array}{l}\text { Tangenina } \\
\text { Verde }\end{array}$ & 1.104 .087 & $169.801,82$ & 0,15 & 335.995 & $59.239,17$ & 0,18 & 972.249 & $175.004,82$ & 0,18 \\
\hline Laranja & 406.906 & $107,418,60$ & 0,26 & 437.080 & $113.845,56$ & 0,26 & 214.710 & $75.197,59$ & 0,35 \\
\hline Limão & 11.289 & $9.407,96$ & 0,83 & 15.312 & $7.904,94$ & 0,52 & 9.122 & $5.431,84$ & 0,60 \\
\hline Lima & 19.460 & $8.495,40$ & 0,44 & 10.980 & $4.667,20$ & 0,43 & 10.897 & $6.148,20$ & 0,56 \\
\hline Total & 2.807 .699 & $674.455,55$ & 0,24 & 1.527 .765 & $446.488,70$ & 0,29 & 2.873 .512 & $826.309,37$ & 0,29 \\
\hline
\end{tabular}

Figura 04 - Produção e preço pago por kg aos produtores da Ecocitrus de 2008 a 2010

Fonte: Elaborado pela autora com dados fornecidos pela Cooperativa Ecocitrus

envasamento e a rotulação do produto final. Além disso, dentro da agroindústria existem duas esteiras para a lavagem, a secagem e o polimento das frutas que serão vendidas in natura.

Do total de tangerinas e laranjas maduras colhidas, $40 \%$ é destinado ao processamento de suco e $60 \%$ é voltado para a venda in natura. Mesmo assim, um dos objetivos da cooperativa é destinar a maior parte da produção para a fabricação do suco, uma vez que as frutas para esse fim resultam num custo menor de produção para os produtores, já que não exigem tanto cuidado na colheita e, por isso, necessitam de menor quantidade de mão de obra.

\subsubsection{Comercialização e logística}

A cooperativa comercializa apenas a produção dos sócios. A oferta de fruta in natura ocorre entre Abril e Novembro, diferente do suco cítrico que possui disponibilidade durante todo o ano, em função da grande capacidade de estocagem nas câmaras frias da cooperativa. As frutas não permanecem armazenadas nas propriedades dos sócios, elas são enviadas imediatamente para a agroindústria da cooperativa após a colheita, através de um caminhão da cooperativa que busca as frutas na propriedade. Dessa forma, a lavagem, a classificação, o processamento e o acondicionamento das frutas são realizados nas dependências da entidade.

Os produtores entregam $100 \%$ da produção de citros para a cooperativa, a qual se responsabiliza pelo restante dos processos. O preço é pago por quilograma e conforme a qualidade, o tamanho da fruta e principalmente conforme o destino final (venda in natura, suco ou óleo). O produtor toma conhecimento do valor final a ser pago pelo seu montante de frutas normalmente em assembléias realizadas com todos os sócios.

Os produtores mostram-se muito satisfeitos com o canal de comercialização adotado pela cooperativa, uma vez que ela representa uma garantia de compra da produção total. Ela fornece ao produtor um relatório da classificação das frutas conforme a qualidade, tamanho, cor e preço pago por quilograma. O pagamento é feito em no máximo 30 dias e, até o presente momento, não houve casos de atraso de pagamentos entre cooperativa e produtores sócios. Conforme os produtores entrevistados, os preços pagos pela cooperativa são maiores que os preços pagos no mercado. Ou seja, a fruta certificada é valorizada, não somente pelo diferencial de preço recebido pelos produtores, mas também pelo fato da cooperativa acessar nichos de mercado específicos. A cooperativa realiza as vendas com os clientes via contrato formal no mercado doméstico e internacional.

Além disso, pelo fato de exigir um controle da produção dos sócios, há o funcionamento de um sistema de rastreabilidade, em que cada produtor possui um número, denominado de "lote". Quando chegam na agroindústria, processam-se todas as frutas referentes a determinado produtor. Isso garante segurança no processo, uma vez que identificado qualquer problema em algum lote, imediatamente será localizado o produtor e a árvore frutífera que apresentou alguma irregularidade (como seria o caso da presença de algum resíduo químico).

Os produtos comercializados pela cooperativa são vendidos nas formas in natura, suco e óleo 
essencial. Os produtores que fazem parte da cooperativa não participam das negociações com os compradores e alegam satisfação quanto a isso, pois não obtém problemas de pagamento ou cumprimento das entregas programadas.

A fruta in natura é vendida para redes de supermercados de Porto Alegre, Santa Catarina, São Paulo e Rio de Janeiro, e outra parte é destinada para a merenda escolar (CONAB). O cliente da Companhia de Entrepostos e Armazéns Gerais de São Paulo (CEAGESP) vende somente alimentos orgânicos e paga um preço diferencial tanto pelo suco quanto pela fruta in natura, o que não acontece com outros dois clientes que representam grandes redes de supermercados.

Para a cooperativa, o principal problema enfrentado na comercialização é relacionado às grandes redes de supermercados, que vêem a fruta como um produto que deve atender apenas requisitos de tamanho e cor, não importando-se com o diferencial de produção. As grandes redes supermercados fazem, inicialmente, propostas boas para a cooperativa; no entanto, ao decorrer das relações comerciais, os supermercados passam a alterar as negociações, como seria o caso da cobrança pela limpeza e aluguel das caixas das frutas, cobrança do transporte até o supermercado, etc. Assim, os contratos vão se modificando e se ajustando conforme as decisões das grandes redes.

A fruta in natura não pode ser exportada porque uma das exigências fitossanitárias de comércio exterior para o caso das frutas frescas (citros) é a utilização de fungicida para combater a doença conhecida como "pinta-preta". No entanto, como a cooperativa não utiliza qualquer tipo de agroquímicos, a comercialização da fruta in natura para outros países não é possível.

Dessa forma, a cooperativa considera que a agroindustrialização de frutas orgânicas e a exportação desses produtos como sendo uma opção mais rentável. A fruta in natura produzida pela cooperativa tem foco apenas no mercado interno, sendo que outra maneira de escoar a produção são as feiras, mas estas são viáveis economicamente apenas para aquelas famílias com menor produção.

Em relação aos compradores externos existem variadas exigências, sendo que a principal é a presença do selo de orgânico (IBD) nos produtos comercializados. Ao mercado internacional é destinado o suco de tangerina e de laranja e o óleo essencial de tangerina. Segundo também noticiado pelo Hasse (2010), para escapar da ação dos intermediários, que atuam em $80 \%$ da produção regional de frutas cítricas, a Ecocitrus trabalha a ideia de formar uma indústria de sucos de porte maior e também com o processamento de extração de óleos essenciais de tangerina, num investimento total de 3 milhões de reais.

Não se obtiveram muitas informações detalhadas sobre a produção e comercialização do suco pela cooperativa. Soube-se apenas que em média um terço do volume total de suco produzido é exportado para a Holanda, onde posteriormente é encaminhado para outros países como Alemanha, Itália e França. O restante é destinado para o mercado interno, principalmente para Porto Alegre-RS e São Paulo-SP (CEAGESP).

O óleo essencial surgiu como uma forma de utilizar as frutas resultantes do raleio. Em 1980, iniciou-se a atividade de raleio com dois produtores que hoje fazem parte da cooperativa. Estes retiravam algumas frutas verdes para dar espaço a frutas maiores e formar frutas com maior qualidade. Com isso, conseguiram atingir seus objetivos, de modo que, após dois ou três anos, outros produtores começaram aderir à técnica. Na região do Vale do Caí, 30.000 toneladas de bergamotas verdes provem do raleio. Destaca-se que, no Brasil, existem apenas cinco indústrias que processam o óleo da tangerina, mas o óleo essencial orgânico é produzido somente pela Ecocitrus.

Em 2010, ano de início do processamento do óleo, foram produzidas cinco toneladas. A cooperativa considera a demanda muito superior ao volume produzido. Por ser um produto inflamável, não pode ser transportado via aérea para o mercado europeu, utilizando assim o transporte fluvial. Assim, eles vendem toda a produção para um intermediário da Europa, via contrato formal, que recebe uma comissão e faz a distribuição para seus clientes. As partes já se visitaram, aumentando a segurança da comercialização e estreitando os laços das negociações. A relação comercial com esse comprador é considerada vantajosa pela cooperativa pois é destinada toda a produção para este único cliente, devido a logística e ao volume comercializado. As perspectivas para a venda do óleo são positivas e os motivos pelos quais optaram em entrarem nesse ramo foram: a existência de um nicho de mercado e uma forma de utilização das tangerinas oriundas do raleio.

Com relação ao limão, mesmo não representando foco principal na cooperativa, também possui destino certo e consolidado. Apenas um terço da produção de limão é destinado aos supermercados nacionais, o restante é enviado a um intermediário na Europa, que faz sorvete orgânico. A cooperativa 
considera esse mercado de sorvetes orgânicos com uma nova tendência mundial.

\subsection{Problemas da cooperativa}

Os principais problemas apontados pelos produtores são: os fatores climáticos, que possuem influência direta sobre a produção e os preços, e a escassez de mão de obra no meio rural. Em 2003 e 2007, o granizo trouxe grandes danos para a produção, pois as pedras danificaram a fruta que já estava no pé e também a floração da próxima safra. Em 2009, as geadas também causaram danos na florada trazendo mais prejuízos para os fruticultores da região. Em 2010, houve uma recuperação no setor e em 2011 uma nova chuva de granizo atingiu parte algumas localidades e prejudicou parte das plantações dedicadas à citricultura.

Outro problema apontado como barreira para o crescimento da produção em cada unidade agrícola é a escassez de mão de obra disponível para trabalhar nas épocas de raleio e colheita dos citros. Poucas pessoas estão dispostas a trabalhar nas diferentes situações que assolam o dia-a-dia dos trabalhadores rurais e a cumprir as exigências que o mercado impõe para uma fruta de qualidade. Além disso, os produtores apontam que a falta de qualificação da mão de obra dificulta ainda mais a utilização da mesma, pois quando os funcionários não seguem as normas e procedimentos de colheita e raleio, conforme o solicitado pelos proprietários e impostas pelo mercado, acabam ocasionando má formação da fruta, estragos na fruta madura no manuseio e colheita de frutas não maduras o suficiente. Dessa forma, o empenho e a dedicação da família são essenciais para a qualidade e sucesso das colheitas.

As doenças nas frutas e árvores também foram apontadas pelos produtores como preocupantes para a fruticultura, principalmente por produzirem de modo orgânico. Os alimentos orgânicos devem ser isentos de produtos químicos e as doenças e pragas são combatidas com tratamentos alternativos. Nota-se um esforço muito grande na difusão de novas técnicas da cooperativa aos produtores e na realização de parcerias com universidades e centros de pesquisa. Porém, percebe-se que as pesquisas voltadas ao cultivo de citros orgânico ainda são escassas, se comparadas a outras variedades de culturas agrícolas. Apesar dos problemas enfrentados, os produtores mostram-se satisfeitos com a atividade que desempenham em conjunto com outros sócios na cooperativa.

\subsection{Perspectivas da cooperativa}

As perspectivas para a cooperativa compõem a pauta de discussões nas assembléias e reuniões, em que a opinião de todos os sócios é levada em conta. Uma das ideias levantadas é voltar-se principalmente para a agroindustrialização dos produtos oriundos das frutas cítricas cultivadas. De acordo com os produtores e responsáveis pela cooperativa, isso possibilita agregação de valor e maior rentabilidade. No caso do suco, os custos são menores para as tangerinas cultivadas para esse fim, pois não há necessidade de tantos cuidados na colheita e basta a utilização da mão de obra familiar. Dessa forma, a estratégia viável economicamente é destinar a maior parte para a produção de sucos, uma vez que possuem a agroindústria internalizada na cooperativa.

Além disso, a cooperativa tem grandes perspectivas para o mercado de óleos essenciais orgânicos, pois considera a demanda muito superior ao volume produzido, e também pelo fato de ter analisado esse mercado antes de serem feitos os investimentos. Ou seja, a cooperativa tem planejamento e repassa isso aos seus sócios, ganhando mais confiança na atuação no mercado.

O novo nicho de mercado, na opinião da cooperativa, é para a linha de perfumaria e cosméticos orgânicos, que já existe principalmente na Alemanha. O selo que certifica esses produtos normalmente é o EcoControl. E, por fim, outra ideia que está em discussão na cooperativa é a possibilidade da adoção de um novo selo de certificação, o Kosher, para atender o mercado judeu nos Estados Unidos (os produtos com esse selo são preparados sob a supervisão de um rabino).

\section{CONCLUSÕES}

A citricultura desenvolve importante papel no Vale do Caí-RS. Com a grande quantidade de produtores na região, a cooperativa Ecocitrus encontrou um meio de diferenciar-se no mercado e possibilitar o crescimento econômico de pequenos produtores. Juntamente com a decisão de voltar-se a produção orgânica, a cooperativa implantou a usina de compostagem que viabilizou essa ideia. E, além disso, criou uma agroindústria que possibilitou a produção do óleo essencial da tangerina e do 
suco de tangerina e de laranja.

O planejamento e o desenvolvimento da cooperativa Ecocitrus foi motivo da atenção de muitos pesquisadores e noticiários nacionais e internacionais. Existem outras associações de citricultores na região do Vale do Caí-RS, sendo que, segundo entrevista de Hasse (2010) com José Stoffel (presidente da Associação Montenegrina de Fruticultores da mesma região), a Ecocitrus é considerada um exemplo, "pois trabalha pela união e prosperidade de todos".

Dessa forma, adotando a verticalização dos processos produtivos e agroindustriais, a cooperativa promoveu um upgrade dos sócios, que antes disso eram apenas pequenos produtores rurais vulneráveis as oscilações do mercado e extremamente dependentes da figura do intermediário. A cooperativa, através do planejamento e divisão das funções, promoveu o crescimento dos produtores e possibilitou a adoção da certificação orgânica e outros selos, que, em função da burocracia e altos custos, se torna praticamente inacessível para apenas um produtor rural. Isso fez com que os produtores pudessem acessar, por meio da cooperativa, canais de comercialização mais sofisticados e conseguissem diferenciar-se no mercado.

A cooperativa continua com grandes perspectivas de crescimento no mercado e de beneficiar os sócios. O grupo está buscando a expansão no setor do óleo essencial orgânico de tangerina, sorvete de limão orgânico e sucos. Além disso, a cooperativa almeja alcançar novas certificações.

Através da pesquisa realizada, percebe-se que a presença da cooperativa é um dos elementos chave para o desenvolvimento da citricultura nesta região, principalmente para os pequenos produtores, uma vez que a instituição proporciona aos seus membros diversas vantagens competitivas. Algumas dessas vantagens são: a) produção em escala, ou seja, a possibilidade de realizarem as vendas em conjunto proporciona o acesso a mercados que exigem grandes quantidades de produtos, atingindo preços melhores e eliminando o papel dos intermediários; b) poder de barganha na compra de insumos e serviços devido a maior quantidade requisitada; c) difusão do conhecimento, através da troca de informações entre os sócios, pesquisas realizadas e a promoção de cursos e palestras pela cooperativa; d) utilização de instalações, máquinas e equipamentos de uso em comum, sendo que as compras destes é difícil individualmente, mas é facilitada quando é em grupo; e) assistência técnica e qualificação através de especialistas da cooperativa, sem custo direto aos produtores sócios; f) processo de certificação, possibilitado pela cooperativa, uma vez que, por se tratar de um processo demorado e exigente, não seria adquirida por grande maioria dos produtores individuais. Os grandes esforços para conseguir os certificados e cumprir com as exigências na cadeia agroindustrial de produtos alimentícios são resultados de um trabalho em equipe de organização e controle.

Ou seja, o papel do cooperativismo no agronegócio brasileiro representa uma forma de incluir os pequenos produtores em técnicas diferenciadas e que, muitas vezes, são dificultadas na atuação individual. Uma associação ou cooperativa possibilita a inserção do pequeno produtor no mercado competitivo e, através da parceria com órgão de pesquisa, promove o crescimento do setor e a diferenciação deste, agregando valor à matéria-prima oriunda do meio rural. Além disso, através de uma cooperativa, é possível determinar a viabilidade econômica da produção agrícola, pois o controle dos custos é realizado e é feita a estimativa de lucros ou prejuízos. Este é um fator determinante no sucesso em qualquer ramo da atividade econômica, mas ainda é pouco encontrado na realidade da pequena produção agropecuária brasileira. Assim, a viabilização da propriedade rural está na qualidade gerencial, ou seja, na boa administração e condução das atividades.

O investimento em pesquisa e desenvolvimento é muitas vezes dificultado para a figura de um pequeno produtor, que tem limitações no acesso a informações e de assistência técnica. No entanto, através da união formal dos produtores na figura de uma associação ou cooperativa, com a divisão de tarefas e o planejamento, o acesso a inovação, ao conhecimento e a diferenciação da produção são fatores possíveis de serem alcançados.

Assim, sugere-se a realização de mais estudos como este, com outras cooperativas agropecuárias do Brasil, a fim de verificar o papel e a importância do cooperativismo na realidade local e principalmente do pequeno produtor rural. Além disso, pretende-se, num trabalho posterior a este, fazer um estudo comparativo entre os produtores ligados ao cooperativismo e aqueles que atuam individualmente no mercado citrícola da região do Vale do Caí-RS, para então fazer uma diferenciação entre as duas formas de atuação no mercado. 


\section{REFERÊNCIAS}

BATALHA, M. O.; SILVA, A. L. da. Gerenciamento de sistemas agroindustriais: definições, especificidades e correntes metodológicas. In: BATALHA, M. O. (Coord.). Gestão agroindustrial. São Paulo: Atlas, 2009.

BIALOSKORSKI NETO, S. Agronegócio cooperativo. In: BATALHA, M. O. (Coord.). Gestão agroindustrial. São Paulo: Atlas, 2009.

BIZZO, H. R.; HOVELL, A. M. C.; REZENDE, C. M. Óleos essenciais no Brasil: aspectos gerais, desenvolvimento e perspectivas. Química Nova, São Paulo, v. 32, n. 3, p. 588-594, 2009.

BRASIL. Constituição da República Federativa do Brasil: promulgada em 5 de outubro de 1988. Presidência da República Federativa do Brasil, Casa Civil, Brasília, DF, 1988.

BRASIL. Lei n. 5.764, de 16 de dezembro de 1971. Altera a legislação tributária federal. Presidência da República Federativa do Brasil, Casa Civil, Brasília, DF, 1971.

CLARO, D. P. et al. O complexo agroindustrial das flores do Brasil e suas peculiaridades. Revista de Administração da UFLA, Organizações Rurais e Agroindustriais, Lavras, v. 1, n. 2, p. 17-30, 1999.

DAVIS, J. H.; GOLDBERG, R. A. A concept of agribusiness. Harvard University: Boston, 1957.

ECOCITRUS. Cooperativa Ecocitrus. 2010. Disponível em: <http://www.ecocitrus.com.br/ cooperativa.htm>. Acesso em: 24 fev. 2012.

ECOVIDA. Rede de Agroecologia Ecovida. 2012. Disponível em: <http://www.ecovida.org. br/a-rede/>. Acesso em: 24 fev. 2012.

FAIRTRADE. Fairtrade - Comércio Justo. 2007. Disponível em: <http://www.it2web.com/ sites/fairtrade/oquee.asp>. Acesso em: 24 fev. 2012.

FERREIRA, J. M. Gestão do agronegócio cooperativo. Revista do Núcleo Interdisciplinar de Pesquisa e Extensão do UNIPAM, Patos de Minas: UNIPAM, v. 6, p. 163-172, 2009.

FRANKE, W. Direito das sociedades cooperativas: direito cooperativo. São Paulo: Saraiva, 1973.

GIL, A. Como elaborar projetos de pesquisa. São Paulo: Atlas, 2009. P. 41-57.

GIMENES, R. M. T.; GIMENES, F. M. P. Agronegócio cooperativo: a transição e os desafios da competitividade, Rev. Ciên. Empresariais da UNIPAR, Umuarama, v. 7, n. 1, p. 33-46, 
2006.

HASSE, G. A rainha da primavera. Globo Rural, ed. 299, set. 2010.

IBD. Instituto Biodinâmico de Certificações. 2012. Disponível em: <http://www.ibd.com.br/ pt/QuemSomos.aspx>. Acesso em: 10 dez. 2012.

IBGE. Instituto Brasileiro de Geografia e Estatística. Produção Agrícola Municipal. 2011. Disponível em: <http://www.sidra.ibge.gov.br/bda/tabela/protabl. asp?c=1613\&z=t\&o=11\&i=P>. Acesso em: 12 dez. 2012.

JERÔNIMO, F. B.; MARASCHIN, A. de F.; SILVA, T. N. da. A gestão estratégica de sociedades cooperativas no cenário concorrencial do agronegócio brasileiro: estudo de caso em uma cooperativa agropecuária gaúcha. Teoria e Evidência Econômica, Passo Fundo, v. 14, n. 26, p. 71-90, 2006.

LAZZARINI, S. G. Estudos de Caso para Fins de Pesquisa: Aplicabilidade e Limitações do Método. In: FARINA et al. (Coord.). Estudos de Caso em Agribusiness. São Paulo: Pioneira, 1997. p. 9-23.

MENDES, J. T. G.; PADILHA JUNIOR, J. B. Agronegócio: uma abordagem econômica. São Paulo: Pearson Prentice Hall, 2007. P. 45-63.

NEVES, M. F. et al. O Retrato da Citricultura Brasileira. In: NEVES, M. F. (Coord.). 1. ed. Ribeirão Preto: Markestrat, 2010. 138 p.

NEVES, M. F. Sistema agroindustrial citrícola: um exemplo de quase-integração no agribusiness brasileiro. 1995. 83 f. Dissertação (Mestrado em Administração de Empresas) - Faculdade de Economia, Administração e Contabilidade, Universidade de São Paulo, 1995.

OCB. Apresentação Institucional Sistema Cooperativista. Organização das Cooperativas Brasileiras, 2011. Disponível em: <http://www.brasilcooperativo.coop.br/GERENCIADOR/ ba/arquivos/140411_apresentacaoinstitucional2010_1.pdf>. Acesso em: 15 mai. 2012.

PREFEITURA MUNICIPAL DE MONTENEGRO. Secretaria Municipal de Agricultura e Meio Ambiente de Montenegro: dados citricultura. Rio Grande do Sul, 2011. Disponível em: <http:// www.montenegro.rs.gov.br/home/show_page.asp?user=\&id_CONTEUDO=2098\&codID_ CAT=503\&imgCAT=\&id_SERVICO=\&categoria=Munic\%EDpio>. Acesso em: 05 mai. 2011.

SESCOOP. Serviço Nacional de Aprendizagem do Cooperativismo. Relatório de Gestão do Exercício de 2011. Brasília, 2011

SILVA, L. C. da. Integração vertical contratual no agronegócio: um estudo no complexo 
agroindustrial da mandioca em Deodápolis, MS. 2006. 119 f. Dissertação (Programa de Pós-Graduação em Engenharia de Produção) - Faculdade de Engenharia Mecânica e de Produção da Universidade Metodista de Piracicaba, Santa Bárbara d'Oeste, 2006.

SLOW FOOD BRASIL. Produtos do Brasil na Arca do Gosto: Bergamota Montenegrina. 2007. Disponível em: <http://www.slowfoodbrasil.com/arca-do-gosto/produtos-dobrasil/46-bergamota-montenegrina>. Acesso em: 10 dez. 2012.

SOUZA, A. S. de. Cooperativismo: uma alternativa econômica. Rio de Janeiro: CECRERJ, 1990. 76 p.

ZYLBERSZTAJN, D. Conceitos gerais, evolução e apresentação do sistema agroindustrial. In: ZYLBERSZTAJN, D.; NEVES, M. F. (Orgs.). Economia e Gestão dos Negócios Agroalimentares. São Paulo: Pioneira Thomson Learning, 2005. 